\title{
EValuation of Lumbar Transforaminal Epidural INJections With Needle Placement and Contrast Flow Patterns: A Prospective, Descriptive RePort
}

\author{
Laxmaiah Manchikanti, MD, Kim A. Cash, RT, Vidyasagar Pampati, MSc,
} Kim S. Damron, RN, and Carla D. McManus, RN, BSN

Background: Transforaminal epidural steroid injection is one of the commonly employed modalities of treatment in managing nerve root pain. However, there have been no controlled prospective evaluations of epidural and nerve root contrast distribution patterns and other aspects of fluoroscopically directed lumbosacral transforaminal epidural steroid injections.

Objectives: To evaluate contrast flow patterns and intravascular needle placement of fluoroscopically guided lumbosacral transforaminal epidural injections.

Design: A prospective, observational study.

Among the three approaches available to access the lumbar epidural space, the transforaminal approach is considered to be the most target-specific with the least volume in fulfilling the aim of reaching the primary site of pathology (ventral and lateral epidural space), compared to interlaminar and caudal approaches (13). Thus, transforaminal epidural injections in the lumbar region have been proposed as not only a target-specific modality of treatment for the management of lumbar pain, but also significantly advantageous with long-term effectiveness $(1,2)$. However, several disadvantages of the transforaminal approach include intraneural injection, neural trauma, technical difficulty in the presence of fusion and/or hardware, intravascular injection, and spinal cord trauma (1-8). A number of randomized evaluations (9-16) and numerous non-randomized evaluations have shown positive short-term and

From Pain Management Center of Paducah, Paducah, Kentucky. Address Correspondence: Laxmaiah Manchikanti, MD, 2831 Lone Oak Road, Paducah, Kentucky 42003.

E-mail: drm@apex.net

Support:There was no external funding in preparation of this manuscript

Conflict of Interest: None
Methods: A total of 100 consecutive patients undergoing fluoroscopically guided transforaminal epidural steroid injections were evaluated. The contrast flow patterns, ventral or dorsal epidural filling, nerve root filling, C-arm time, and intravascular needle placement were evaluated.

Results: Ventral epidural filling was seen in $88 \%$ of the procedures, in contrast to dorsal filling noted in $9 \%$ of the procedures. Nerve root filling was seen in $97 \%$ of the procedures. Total intravenous placement of the needle was noted in $22 \%$ of the procedures, whereas negative flashback and aspiration was noted in $5 \%$ of the procedures.

Conclusion: Lumbosacral transforaminal epidural injections, performed under fluoroscopic visualization, provide excellent nerve root filling and ventral epidural filling patterns. However, unrecognized intravascular needle placement with negative flashback or aspiration was noted in $5 \%$ of the procedures.

Keywords: Chronic low back pain, nerve root pain, lumbosacral transforaminal epidural injection, fluoroscopy, ventral epidural contrast flow long-term effectiveness of transforaminal epidural steroids in managing nerve root pain. A common problem encountered with an epidural injections is inaccurate needle placement, which also results in inaccurate placement of the injectate. However, with the transforaminal epidural approach, the target site is approached more ventrally, along with delivery of injectate where the posterior annulus interfaces with the ventral aspect of the nerve root and the thecal sac $(4,17)$.

Furman et al (4) reported a high incidence of intravascular injections in lumbar transforaminal epidural injections that is significantly increased at S1. They reported the overall rate of intravascular injection as $11.2 \%$. Further, they reported that using flash or positive blood aspirate to predict intravascular injections was highly specific $(97.9 \%)$ but sensitivity was low (44.7\%). Manchikanti et al (18) in their evaluation of fluoroscopically guided caudal epidural injections reported ventral epidural filling in $69 \%$ of the patients, whereas Botwin et al (19) reported ventral spread of contrast in 36\% of their patients with fluoroscopically guided lumbar interlaminar epidural injections.

None of the published studies to date have evaluated epidural and nerve root flow patterns with transforaminal lumbosacral epidural injections. This prospective, observational study was undertaken to evaluate epidural and nerve root filling patterns and evaluate intravascular needle placement with lumbosacral epidural injections.

\section{Methods}

This prospective evaluation of lumbosacral transforaminal epidural injections under fluoroscopy was undertaken in an interventional pain management practice, a specialty referral center, in a private practice setting.

\section{Informed Consent}

All patients were provided an explanation of the purpose for this study and an opportunity for discussion. They were also advised of the associated risks and given the choice as to whether or not they wanted to participate. Informed consent was then obtained.Appropriate precautions were taken to protect the privacy and conceal the identity of the patients participating in this study.

Inclusion criteria were consecutive patients undergoing transforaminal epidural injection(s). Exclusion criteria in- 
cluded pregnant or lactating women, patients with history of adverse reaction to local anesthetic, steroid, or contrast, patients unable to understand the informed consent or patients unable to be positioned in the prone position to perform the procedure.

The evaluation included demographic data of age, gender, weight, height, history of previous surgery, distribution of pain, and magnetic resonance imaging (MRI) or computerized tomog- raphy (CT) findings.

\section{Procedure}

A single technique by a single operator was utilized in all cases. All procedures were performed with contrast enhancement in a sterile operating room. The patients were prepared and draped. All procedures were performed in a sterile fashion. Intravenous midazolam was administered to all patients.

For lumbar transforaminal epidu- ral injections, the fluoroscope was positioned so that an appropriate posteroanterior (PA) view was obtained. Local anesthetic infiltration was carried out with a \#25-gauge needle infiltrating $1 \%$ lidocaine, not to exceed approximately $1 \mathrm{~mL}$ per level at the lateral edge and slightly inferior to the transverse process. A \#22gauge dimond tip needle with a stylet was guided towards the neural foramen. Under intermittent fluoroscopy, the needle was advanced into the "safe triangle"

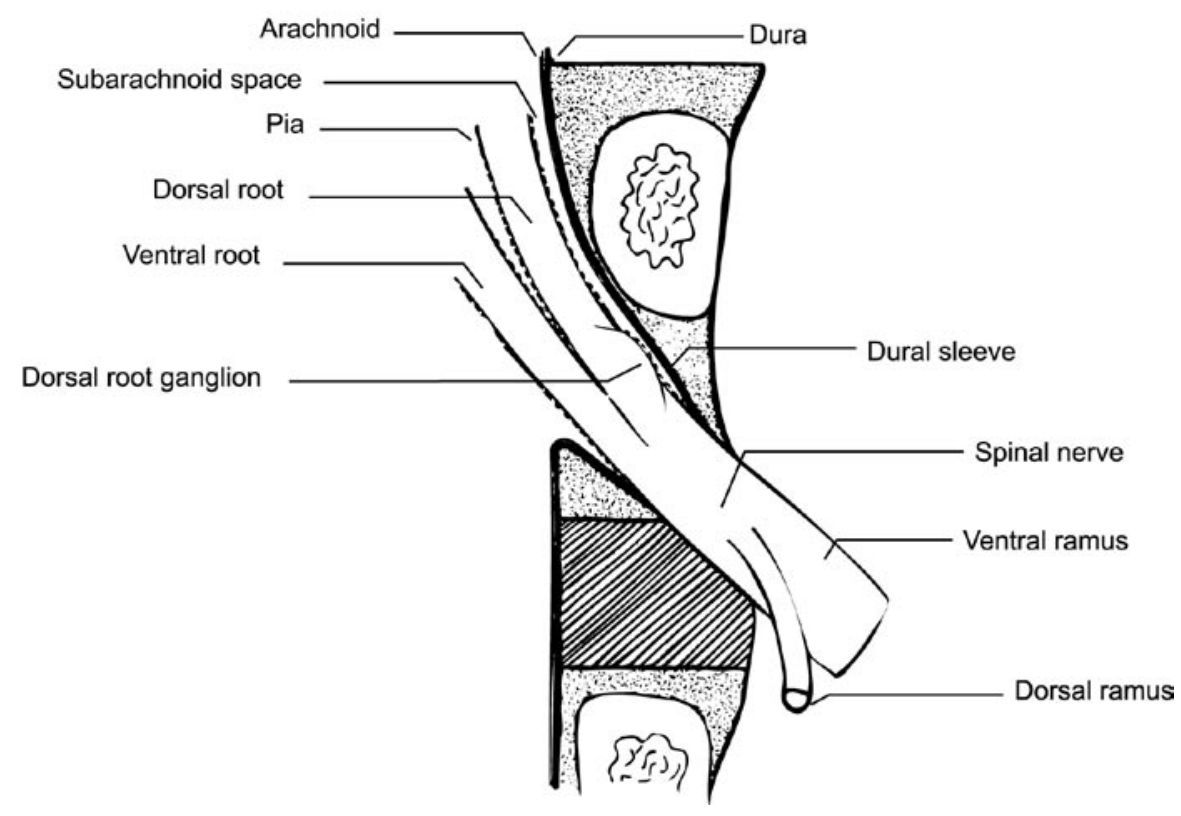

Fig. 1. A sketch of a lumbar spinal nerve, its roots and meningeal coverings. The nerve roots are invested by pia mater and covered by arachnoid and dura as far as the spinal nerve. The dura of the dural sac is prolonged around the roots as their dural sleeve, which blends with the epineurium of the spinal nerve.

Redrawn from Bogduk (20)

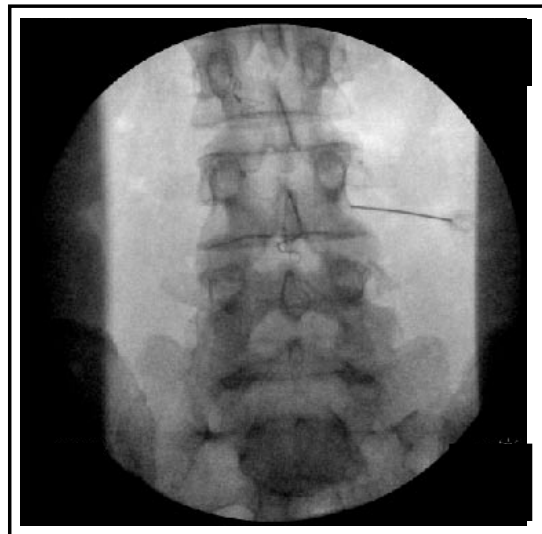

A. Needle Placement in a PA view

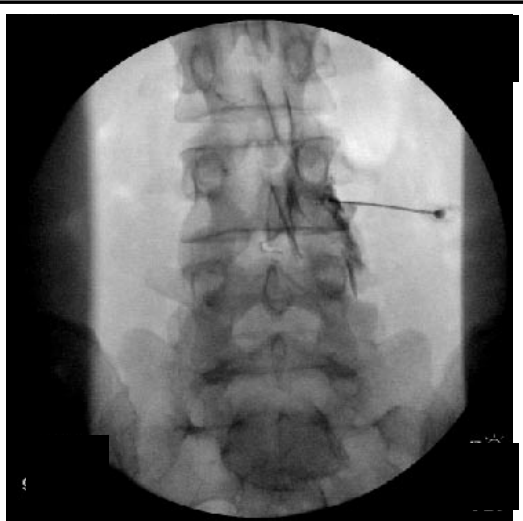

B. Contrast injection with nerve root filling in a PA view

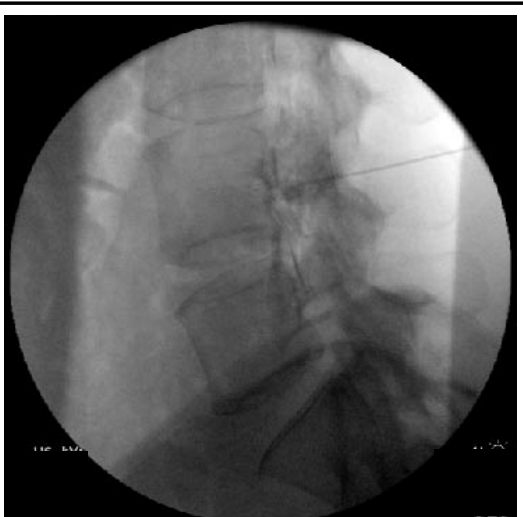

C. Lateral view depiction ventral epidural filling

Fig. 2. Transforaminal epidural injection at L3 
(20), inferior to the pedicle, and superolateral to the exiting spinal nerve (Fig. 1). Presumably, this avoids nerve, dorsal root ganglion, and dural sleeve puncture. Bi-

planar visualization was carried out in all cases (Figs. 2-4).

For S1 transforaminal injections, the \#22-gauge needle was guided into the superior lateral quadrant of the S1 foramen using biplanar fluoroscopy (Fig. 5). Fig. 6 shows intravascular placement at L5, and S1 with lack of flashback and

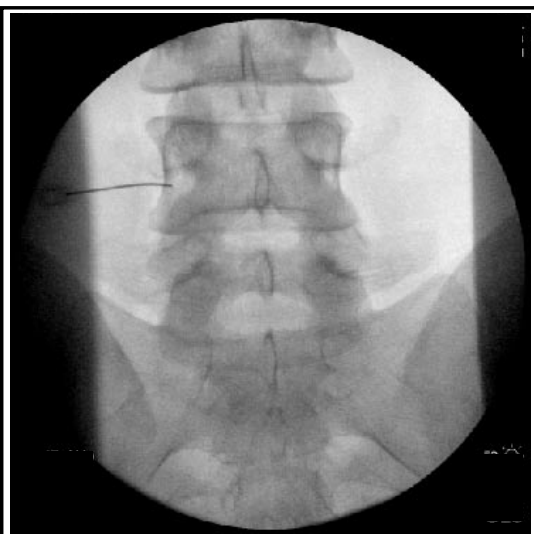

A. Needle Placement in a PA view

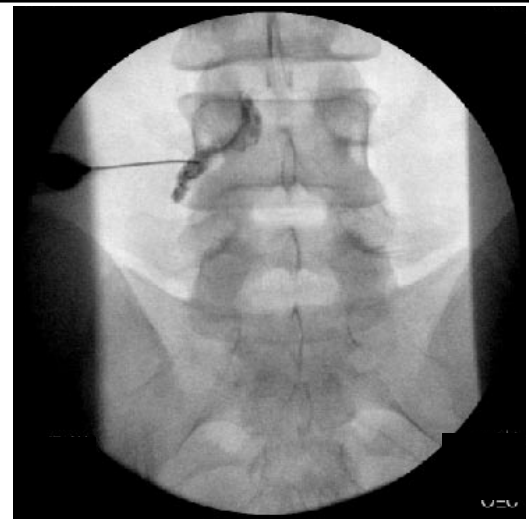

B. Contrast injection with nerve root filling in a PA view

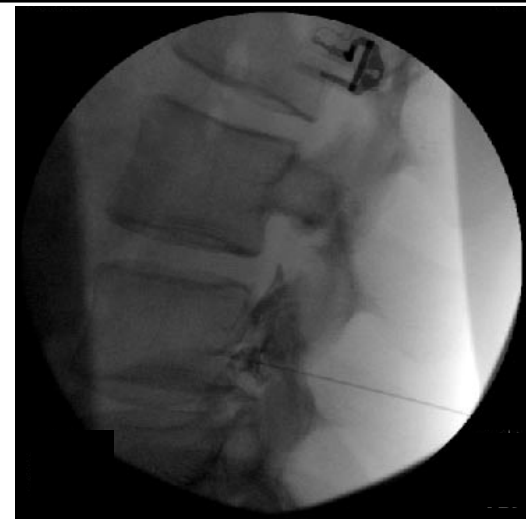

C. Lateral view depiction ventral epidural filling

Fig. 3. Transforaminal epidural injection at L4

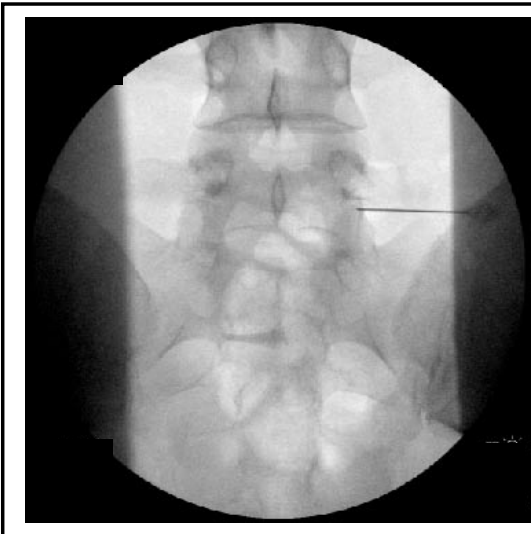

A. Needle Placement in a PA view

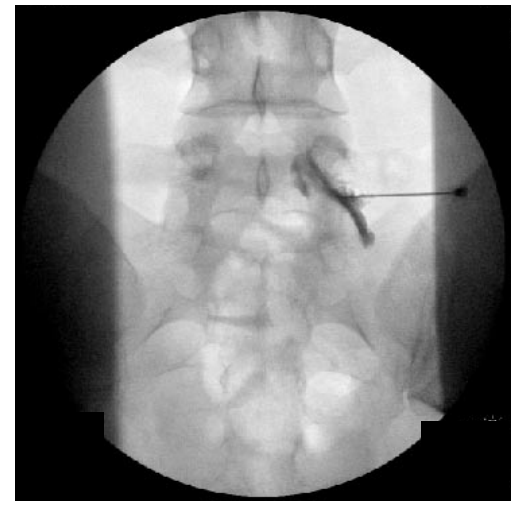

B. Contrast injection with nerve root filling in a PA view

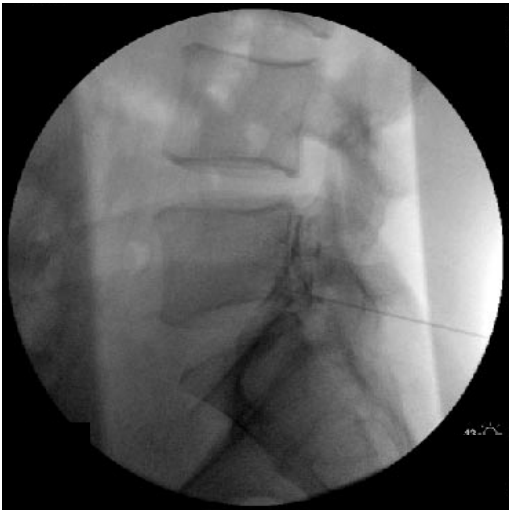

C. Lateral view depiction ventral epidural filling

Fig. 4. Transforaminal epidural injection at L5

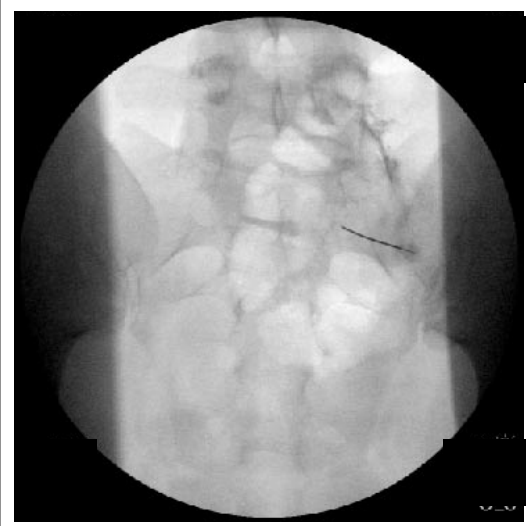

A. Needle Placement in a PA view

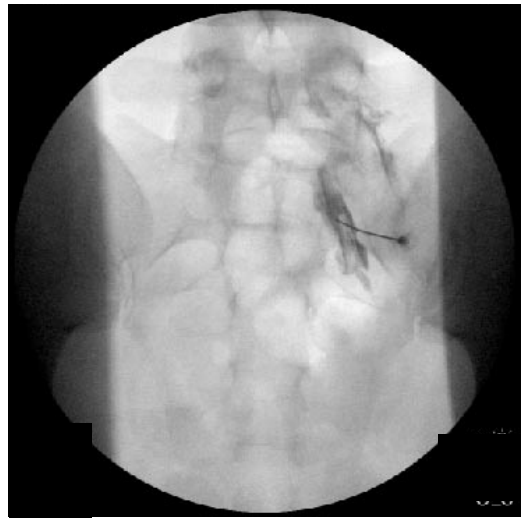

B. Contrast injection with nerve root filling in a PA view

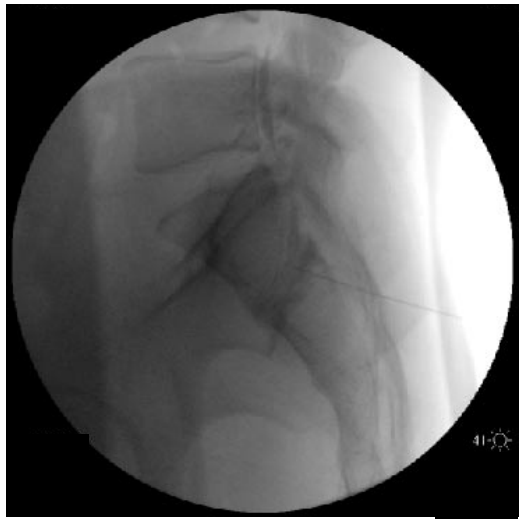

C. Lateral view depiction ventral epidura filling

Fig. 5 . Transforaminal epidural injection at $S 1$ 


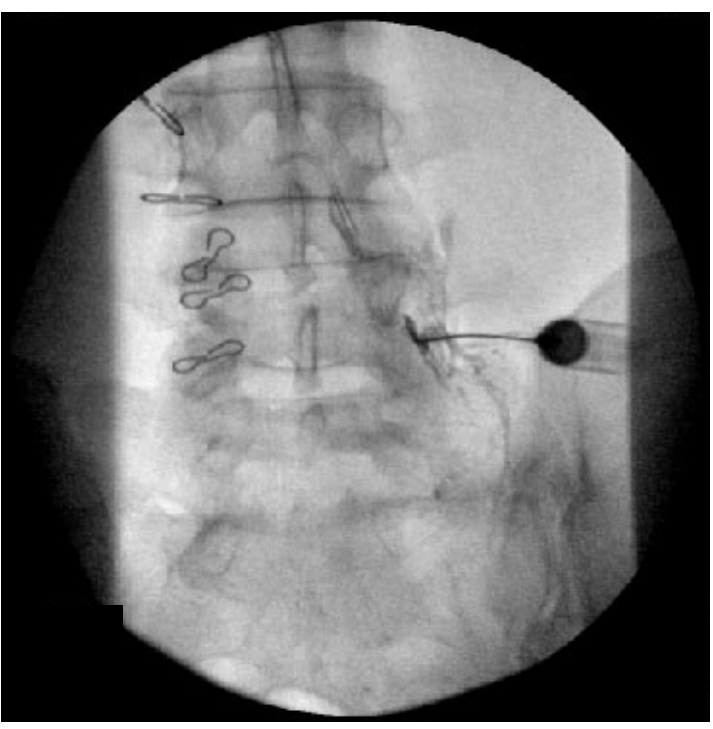

A - L5

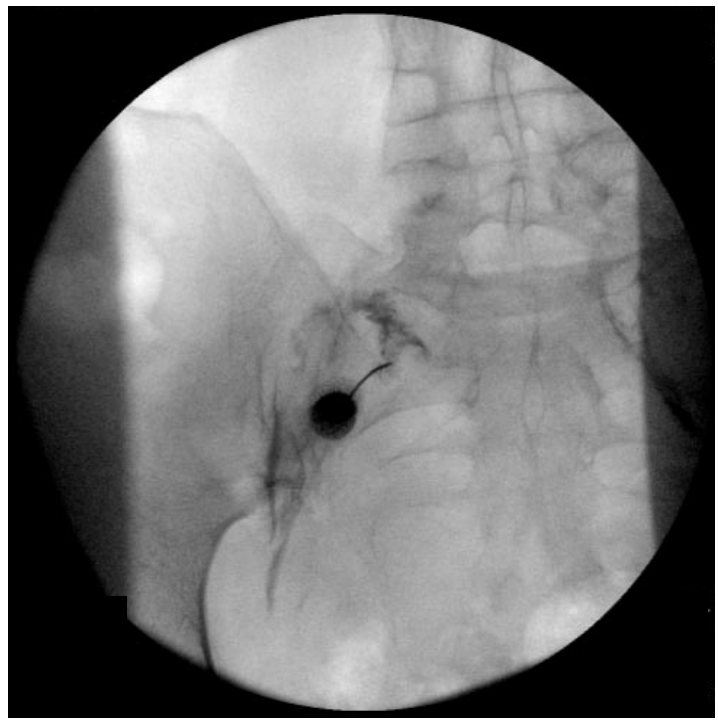

C - S1

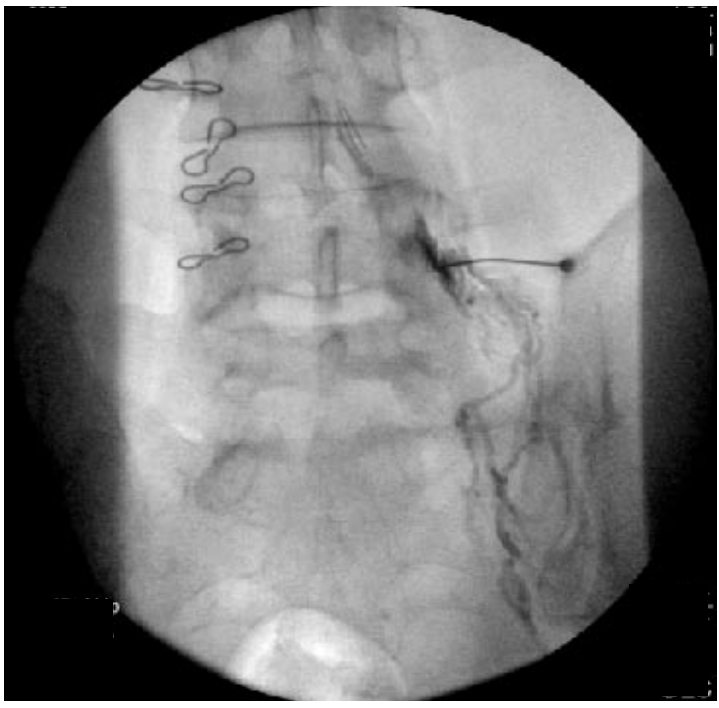

B - L5

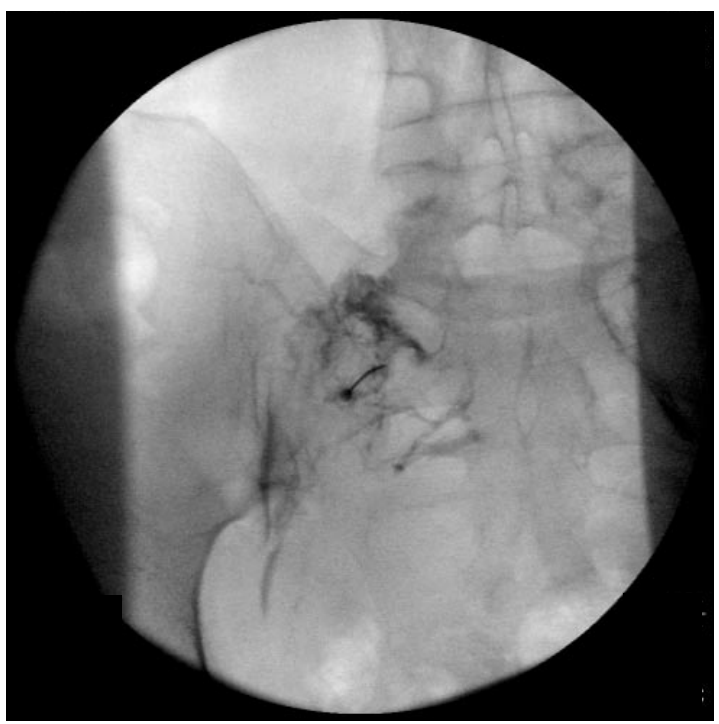

D. S1

Fig. 6. Intravascular placement at L5 and S1

negative aspiration, with typical vascular patterns following contrast injection.

At all levels, 0.5 to $2.0 \mathrm{~mL}$ of nonionic contrast was injected under fluoroscopic visualization. During the injection, presence or absence of vascular spread, as well as nerve root filling were noted. If there was vascular spread, the needle was repositioned. After fluoroscopically confirming a non-vascular injection, $1.0 \mathrm{~mL}$ of $1 \%$ lidocaine, followed by 3 to $6 \mathrm{mg}$ of
Celestone Soluspan (6 mg per $\mathrm{mL}$ ), followed by 0.25 to $1 \mathrm{~mL}$ of lidocaine without epinephrine were injected.

At all levels, after the ideal positioning of the needle, which was confirmed by fluoroscopy, the presence or absence of flash and/or aspiration of blood into the needle hub; needle position and dispersion of contrast into the epidural space and nerve root filling; and pain during injection of contrast, local anesthetic, or steroid were documented. Data were collected on the following aspects: number of attempts, C-arm time in seconds, positive flashback or aspiration, intravenous or intraarticular contrast filling, epidural filling in lateral view, pain during the injection, immediate pain relief, and complications.

Pain relief was graded as none $(0 \%)$, poor (1\%-25\%), fair (26\%-50\%), good (51\%-74\%), excellent (>75\%), and com- 
plete pain relief $(100 \%)$. Evaluation of complications included bleeding, swelling, pain, fever, muscle spasms, soreness at injection site, numbness, weakness, dizziness, nausea or vomiting, voiding difficulty, and other complications as reported by the patients.

\section{Complications}

Complications were evaluated during the procedure, immediately in the postoperative period, and within 24 to 72 hours in the postoperative period.

Data were recorded on a database using Microsoft ${ }^{\circledR}$ Access ${ }^{\circledR}$. The SPSS version 9.0 statistical packages were used to generate the frequency tables and chisquared statistic was used. Results were considered statistically significant if the $P$ value was less than 0.05 .

\section{RESULTS}

\section{Demographics}

Demographic characteristics illustrated a predominantly female population $(60 \%)$ with weight (mean \pm SD) of 187 \pm 55 lbs., mean height of $67 \pm 4$ inches. Twenty-eight percent of the patients underwent previous lumbar surgical intervention with or without fusion.

The pain distribution was bilateral low back pain in $66 \%$ and bilateral lower extremity pain in $30 \%$. Unilateral lower extremity pain was observed in $70 \%$ of the patients.

Structural abnormalities identified by a radiologist, either on computerized tomography (CT) or magnetic resonance imaging (MRI) were evaluated (Table 1).

\section{Procedural Characteristics}

Two hundred fifty-six lumbosacral transforaminal epidural injections were performed on 100 consecutive patients. Table 2 illustrates the levels injected.

The C-arm time (mean $\pm \mathrm{SD}$ ) was $14.4 \pm 9.8$ seconds per patient.

The needle was found to be intravascular in $22 \%$ of the transforaminal injections. The flashback was noted in $13 \%$ of the procedures and positive aspiration without a flashback was noted in $5 \%$ of the procedures (Table 3 ). In $5 \%$ of the procedures, intravascular placement was noted with contrast injections, even though flashback and aspirations were negative. Intravascular penetration was significantly higher with sacral proce- dures accounting to $58 \%$ of all intravascular placements. Sacral intravascular placements were $32 \%$ compared to $16 \%$ lumbar $(\mathrm{p}=0.002)$.

Table 4 illustrates the number of attempts or manipulations of the needle. Appropriate placement was achieved in $63 \%$ of the procedures with one attempt.

\section{Contrast Flow Patterns}

Any filling noted within one-third of the spinal canal close to the ventral surface was considered as ventral filling, whereas,
Table 1. Structural abnormalities as described by radiologist ${ }^{*}$

\begin{tabular}{|l|c|}
\hline Disc degeneration & $42 \%$ \\
\hline Facet arthropathy & $23 \%$ \\
\hline Spinal stenosis & $7 \%$ \\
\hline Disc bulging & $41 \%$ \\
\hline Disc Protrusion & $20 \%$ \\
\hline Disc herniation & $19 \%$ \\
\hline Epidural fibrosis & $5 \%$ \\
\hline No abnormalities & $20 \%$ \\
\hline
\end{tabular}

*Totals may not correlate, as some patients presented with more than one abnormality

Table 2. Transforaminal epidural steroid injections by level

\begin{tabular}{|c|c|c|c|c|c|c|}
\hline Level & L3 & L4 & L5 & S1 & Bilateral & Total \\
\hline Number & 2 & 29 & 113 & 95 & 17 & 256 \\
\hline
\end{tabular}

Table 3. Intravascular placement characteristics

\begin{tabular}{|l|c|c|c|c|c|c|}
\hline & L3 & L4 & L5 & Sacral & Total Lumbar & Total \\
\hline Positive flashback & 1 & 4 & 10 & 18 & 15 & 33 \\
\hline Positive blood aspirate & 0 & 0 & 5 & 7 & 5 & 12 \\
\hline $\begin{array}{l}\text { Positive contrast with } \\
\text { negative flash back and } \\
\text { aspirate }\end{array}$ & 1 & 3 & 8 & 4 & 12 \\
\hline Total intravascular & $\mathbf{1}$ & $\mathbf{5}$ & $\mathbf{1 8}$ & $\mathbf{3 3}^{\mathbf{*}}$ & $\mathbf{2 4}$ & $\mathbf{5 7}$ \\
\hline
\end{tabular}

${ }^{*}$ Indicates significant difference $(P=0.002)$

Table 4. Number of attempts or manipulations of needle per each level

\begin{tabular}{|c|c|c|c|c|}
\hline \multirow{2}{*}{ Level } & \multirow{2}{*}{ No. of Procedures } & \multicolumn{3}{|c|}{ Number of Attempts } \\
\cline { 3 - 5 } & & $\mathbf{1}$ & $\mathbf{2}$ & $\mathbf{3}$ or more \\
\hline L3 & 2 & $50 \%(1)$ & $50 \%(1)$ & 0 \\
\hline L4 & 33 & $58 \%(19)$ & $33 \%(11)$ & $9 \%(3)$ \\
\hline L5 & 119 & $61 \%(72)$ & $24 \%(29)$ & $15 \%(18)$ \\
\hline S1 & 102 & $67 \%(68)$ & $27 \%(28)$ & $6 \%(6)$ \\
\hline Total & 256 & $63 \%(160)$ & $27 \%(69)$ & $10 \%(27)$ \\
\hline
\end{tabular}

Table 5. Contrast flow patterns of epidural filling

\begin{tabular}{|c|c|c|c|}
\hline & \multicolumn{3}{|c|}{ Epidural Filling } \\
\hline Level & Ventral & Dorsal & None \\
\hline L3 (2) & $100 \%(2)$ & 0 & 0 \\
\hline L4 (29) & $83 \%(24)$ & $14 \%(4)$ & $3 \%(1)$ \\
\hline L5 (113) & $90 \%(102)$ & $7 \%(8)$ & $3 \%(3)$ \\
\hline S1 (95) & $87 \%(83)$ & $9 \%(9)$ & $4 \%(4)$ \\
\hline Total (239) & $88 \%(211)$ & $9 \%(21)$ & $3 \%(8)$ \\
\hline
\end{tabular}

() Number of levels (bilateral considered as one level) 
Table 6. Contrast flow patterns of nerve root filling

\begin{tabular}{|c|c|c|}
\hline \multicolumn{3}{|c|}{ Nerve Root Filling } \\
\hline Nerve Root & Yes & No \\
\hline L3 (2) & $100 \%(2)$ & 0 \\
\hline L4 (33) & $94 \%(31)$ & $6 \%(2)$ \\
\hline L5 (110) & $97 \%(115)$ & $3 \%(4)$ \\
\hline S1 (102) & $99 \%(100)$ & $1 \%(2)$ \\
\hline Total (247) & $97 \%(248)$ & $3 \%(8)$ \\
\hline
\end{tabular}

( ) Number of levels (bilateral considered as one level)

filling not within one-third of the ventral area of the spinal canal was considered as dorsal filling.

Tables 5 and 6 illustrate contrast flow patterns of epidural and nerve root filling. Eighty-eight percent of the injections showed ventral filling, whereas, $97 \%$ of the injections showed nerve root filling.

\section{Pain Production and Pain Relief}

Reproduction of pain was seen in the low back in $28 \%$ of the patients, hip in $16 \%$, leg with radicular pattern in $36 \%$ of the patients. Thirty-eight percent of the patients reported no pain during the injection.

Pain relief was seen in all the patients with poor relief in $4 \%$, fair relief in $3 \%$, good relief in $21 \%$, excellent relief in $41 \%$, and complete pain relief in $31 \%$ of the patients in the postoperative period.

\section{Complications}

Soreness at injection site was the

Table 7. Complications ${ }^{*}$
\begin{tabular}{|l|c|}
\hline No complications & $93 \%$ \\
\hline Soreness at injection site & $6 \%$ \\
\hline Increased pain & 1 \\
\hline Muscle spasms & 1 \\
\hline Swelling & $0 \%$ \\
\hline Headache & 1 \\
\hline Minor bleeding & $0 \%$ \\
\hline Dizziness & $0 \%$ \\
\hline Nausea/Vomiting & 1 \\
\hline Fever & $0 \%$ \\
\hline Numbness & $0 \%$ \\
\hline Voiding difficulty & $0 \%$ \\
\hline Vasovagal reaction & $0 \%$ \\
\hline Motor weakness & $0 \%$ \\
\hline Insomnia & $0 \%$ \\
\hline
\end{tabular}

* Some patients experienced more than one complication. Thus, totals may not correlate. most common complication (6\%), with increased pain, muscle spasms, headache, fever, and nausea/vomiting being reported in $1 \%$ in each category. No other complications were noted. Ninety-three percent of the patients had no complications (Table 7).

\section{DISCUSSION}

This prospective evaluation with lumbosacral transforaminal epidural injections showed nerve root filling in $97 \%$ of the injections and ventral epidural filling in $88 \%$ of the patients. Overall, intravascular penetration of the needle was observed in $22 \%$ of the transforaminal procedures. Flashback was seen in only $13 \%$ of the procedures, with an additional $5 \%$ showing positive aspiration for blood. However, in $5 \%$ of the procedures neither flashback nor positive aspiration was observed, but the needle was shown to be intravascular on contrast injection.

The results of this study showed $22 \%$ intravascular placement compared to Furman et al (4) with an incidence of intravascular placement in $11 \%$ of the injections. Sullivan et al (21) also reported intravascular flow in transforaminal epidural steroid injections with an overall intravascular rate of $10.8 \%$ (21). Similar to both the previous studies $(4,21)$, we also observed higher intravascular needle penetration at S1 with $16 \%$ lumbar vs $32 \%$ sacral or $42 \%$ vs $58 \%$ of all intravascular placements. This is attributed to increased vascularity present in the sacral foraminal region.

Epidural filling patterns have not been studied in the past. It is encouraging to note that the majority of the patients in this study have achieved ventral epidural filling, thus, presumably providing a high concentration of corticosteroid delivered precisely to the target site, which is located at the ventral aspect of the lumbar nerve root sleeve and the dorsal aspect of the disc herniation. This confirms the previous investigations of higher ventral filling patterns with transforaminal epidurals (17). This potentially explains the reasons for significantly better results with lumbosacral transforaminal epidural injections. Andrade and Eckman (17) showed that ventral filling is higher with transforaminal epidurals than caudal epidurals or interlaminar epidural injections. Similarly, the results of this study shows ventral filling in a greater proportion of patients with the transforaminal epidural $(88 \%)$ compared to previous studies where caudal epidural injections had non-specific ventral filling in 69\% (18) and 36\% with interlaminar epidurals (19).

There were no major complications. All the complications were minor. In fact, complications reported in this study were less than with caudal epidural injections reported in the same setting (18) where $34 \%$ of the patients complained of some type of complication compared to only $7 \%$ in this study with the transforaminal approach.

\section{Conclusion}

This prospective evaluation showed successful nerve root and ventral epidural filling in the majority of the lumbosacral transforaminal epidural injections performed with fluoroscopic guidance. This study also showed significant intravascular needle placement $(22 \%)$, with $5 \%$ of the total procedures being negative for flashback, as well as aspiration for blood, even though contrast injection was positive. Soreness at the injection site was the most commonly reported complication by $6 \%$ of the patients.

\section{ACKNOWLEDGMENTS}

The authors wish to thank Tonie Hatton, transcriptionist; Sheila Jackson, RN, Doris E. Brandon, CST, Sue R. Wilson, ORT, and Victoria L. Hicks, ORT; for their assistance in preparation of this manuscript. 


\section{Author Affiliation: \\ Laxmaiah Manchikanti, MD \\ Medical Director 2831 Lone Oak Road \\ Paducah, Kentucky 42003 \\ E-mail:drm@apex.net.}

Pain Management Center of Paducah

\section{Kim A. Cash, RT}

Radiological Technologist

Pain Management Center of

Paducah

2831 Lone Oak Road

Paducah, Kentucky 42003

Vidyasagar Pampati, MSc

Statistician

Pain Management Center of

Paducah

2831 Lone Oak Road

Paducah, Kentucky 42003

E-mail sagar@thepainmd.com

\section{Kim S. Damron, RN}

Nursing Administrator

Pain Management Center of

Paducah

2831 Lone Oak Road

Paducah, Kentucky 42003

Carla D. McManus, RN, BSN

Assistant Nursing Administrator

Pain Management Center of

Paducah

2831 Lone Oak Road

Paducah, Kentucky 42003

\section{References}

1. Manchikanti L, Staats PS, Singh V et al. Evidence-based practice guidelines for interventional techniques in the management of chronic spinal pain. Pain Physician
2003; 6:3-80.

2. Boswell MV, Hansen $H C$, Trescot $A M$ et al. Epidural steroids in the management of chronic spinal pain and radiculopathy. Pain Physician 2003; 6:319-334.

3. Manchikanti L. Transforaminal lumbar epidural steroid injections. Pain Physician 2000; 3:374-398.

4. Furman MB, O’Brien EM, Zgleszewski TM. Incidence of intravascular penetration in transforaminal lumbosacral epidural steroid injections. Spine 2000; 25:26282632.

5. Botwin KP, Gruber RD, Bouchlas CG et al. Complications of fluoroscopically guided transforaminal lumbar epidural injections. Arch Phys Med Rehabi, 2000; 81:10451050.

6. Houten JK, Errico TJ. Paraplegia after lumbosacral nerve root block: Report of three cases. Spine J 2002; 2:70-75.

7. Elias M. A rare cause of radiculopathy following transforaminal epidural steroid injection. Pain Clinic 1998; 11:159-160.

8. Stohr M, Mayer K. Nerve-root damage from local injections. Dtsch Med Wochenschr 1976; 101:1218-1220.

9. Kraemer J, Ludwig J, Bickert $U$ et al. Lumbar epidural perineural injection: A new technique. Eur Spine J 1997; 6: 357-361.

10. Silva J, Costa AO, Simoes MT et al. Management of radicular pain from lumbar herniated disc using betamethasone epidural injection. Revista Brasileira de Ortopedia 1999; 34:165-168.

11. Riew KD, Yin Y, Gilula L et al. The effect of nerve-root injections on the need for operative treatment of lumbar radicular pain. J Bone Joint Surg Am, 2000; 82: 1589-1593.

12. Karppinen J, Malmivaara A, Kurunlahti M et al. Periradicular infiltration for sciatica, Spine 2001; 26:1059-1067.

13. Karppinen J, Ohinmaa A, Malmivaara A et al. Cost effectiveness of periradicular infil- tration for sciatica. Spine 2001; 26:25872595.

14. Vad V, Bhat AL, Lutz GE et al. Transforaminal epidural steroid injections in lumbosacral radiculopathy: A prospective randomized study. Spine 2002; 27:11-16.

15. Kolsi I, Delecrin J, Berthelot JM et al. Efficacy of nerve root versus interspinous injections of glucocorticoids in the treatment of disc-related sciatica. A pilot, prospective, randomized, double-blind study. Joint Bone Spine, 67, 113-118, 2000.

16. Thomas E, Cyteval C, Abiad L et al. Efficacy of transforaminal versus interspinous corticosteroid injection in discal radiculalgia - a prospective, randomised, double-blind study. Clin Rheumatol 2003; 22: 299-304.

17. Andrade A, Eckman E. The distribution of radiologic contrast media by lumbar translaminar and selective neural canals in normal human volunteers. In Proceedings of the Annual Meeting of the International Spinal Injection Society, Keystone, CO, January 1992.

18. Manchikanti L, Cash KA, Pampati V et al. Evaluation of fluoroscopically guided caudal epidural injections. Pain Physician 2004; 7:81-92.

19. Botwin KP, Natalicchio J, Hanna A. Fluoroscopic guided lumbar interlaminar epidural injections: A prospective evaluation of epidurography contrast patterns and anatomical review of the epidural space. Pain Physician 2004; 7:77-80.

20. Bogduk N. Nerves of the lumbar spine. In Clinical Anatomy of the Lumbar Spine. Churchill Livingstone, New York, 1997, pp 127-144.

21. Sullivan WJ, Willick S, Chirq-Adisai W et al. Incidence of intravascular uptake in lumbar spinal injection procedures. Presented at the North American Spine Society's $14^{\text {th }}$ Annual Meeting, Chicago IL, October 23, 1999. 
